\title{
CHILDHOOD INJURIES AND DEATHS DUE TO FALLS FROM WINDOWS
}

KIMBERLYE. STONE, MD, BRUCE P. LANPHEAR, MD, MPH, WENDYJ. POMERANTZ, MD, MS, AND JANE KHOURY, MS

\begin{abstract}
Background. Unintentional injuries are the leading cause of death in children, and falls are the most common type of unintentional injury in the US. The incidence of falls from windows, a common cause of death in urban areas, has not been described outside major cities such as New York and Chicago, and rates in urban and suburban areas have not been compared.
\end{abstract}

Objective. To estimate the incidence and identify the population at risk for falls from windows among children in Hamilton County, Ohio.

Design. Retrospective case series identified using Cincinnati Children's Hospital Medical Center (CHMC) Trauma Registry.

Setting. Hamilton County, Ohio, which has urban and nonurban areas.

Participants. Children less than 15 years old residing in Hamilton County, Ohio, presenting to CHMC in Cincinnati, Ohio, after a fall from a window between January 1,1991, and December 31, 1997.

Outcome Measure. Annual incidence by age, race, gender, and residence of those who fell from windows.

Results. Over the 7-year study period, $86(6.3 \%)$ of 1,363 falls were from windows. The mortality rate for falls from windows was $4.7 \%$, compared to $0.07 \%$ for all other falls presenting to CHMC $(P<.0001)$. Children $0-4$ years old had a higher rate of falls than children aged $5-14(14.6 / 100,000$ vs. $2.0 / 100,000)(P<.0001)$. Males were twice as likely to fall as females $(P<.016)$, and black children were three times more likely to fall than non-black children $(P<.002)$. The incidence of falls in the city of Cincinnati was four times that of the non-urban area $(P<.0002)$.

Conclusions. Injuries from falls from windows are a public health problem in Hamilton County, Ohio, especially for young, urban children.

KEY WORDS Childhood Injury, Injury Prevention, Urban Trauma, Window Falls.

Drs. Stone, Lanphear, and Pomerantz and Ms. Khoury are with Children's Hospital Medical Center and Dr. Lanphear and Ms. Khoury are with the University of Cincinnati, Cincinnati, Ohio. Correspondence: Kimberly E. Stone, MD, Department of General and Community Pediatrics, 4357 Ferguson Drive, Suite 150, Cincinnati, OH 45245. (E-mail: kimstonemd@yahoo.com) 
Despite a decline in injury-related deaths among children from 1978 to 1991, injuries still cause substantial morbidity and mortality in children. ${ }^{1}$ Studies that examined the epidemiology of injuries identified risk factors and strategies for prevention in children, leading to dramatic reductions in injuries and deaths among US children. ${ }^{1-4}$ However, injuries are still the leading cause of death in children. ${ }^{1}$

Falls account for significant morbidity and mortality, especially for young children. ${ }^{5,6}$ Falls account for the majority of injury-related emergency room and ambulatory care visits, 5,6 and falls are the sixth leading cause of death in children aged 1-4 years. ${ }^{7}$ In Hamilton County, Ohio, from 1994 to 1996, falls were the second leading cause of injury in children aged 1-4 years and the fourth leading cause of injury-related deaths. ${ }^{8}$ Falls from heights have a particularly high mortality rate. ${ }^{9-11}$

Since the early 1970s, falls from buildings have been recognized as an important cause of injury and death among children. ${ }^{9-17}$ Studies conducted in New York City reported that falls from dwellings accounted for $12-20 \%$ of all injuryassociated deaths. ${ }^{9,10}$ Virtually all deaths in these studies were due to falls from windows, particularly for children who were less than 5 years old. ${ }^{9-17}$ The incidence of falls from windows outside metropolitan areas such as New York City and Chicago is defined poorly. Many cities, including Cincinnati, do not have any regulations requiring window guards, although these guards have been shown to prevent falls. ${ }^{11,16}$

The purpose of this study was to estimate the incidence and identify the population at risk for falls from windows in Hamilton County, Ohio, which may help to determine the magnitude of this problem in smaller urban and suburban areas.

\section{METHODS}

All falls between January 1, 1991, and December 31, 1997, evaluated at Children's Hospital Medical Center (CHMC), the only Level 1 Pediatric Trauma Center in Cincinnati, were identified retrospectively from the Trauma Registry at CHMC. Almost every child younger than 15 years in Hamilton county with trauma requiring emergency medical service response is evaluated at CHMC. Cases were defined for this study as children less than 1.5 years old who unintentionally fell from a window in Hamilton County, Ohio, over the 7-year period. No falls outside Hamilton County were included. Children who fell from roofs, porches, furniture, and playground equipment were excluded. The Trauma Registry includes all children hospitalized for injuries, and data after 1995 include those 
children evaluated in the emergency room and discharged. Death certificates were not evaluated since almost all children with trauma are evaluated at CHMC. Cases were retrieved using the International Classification of Diseases, Ninth Revision (ICD-9) E codes 882 (fall from building) and 884 (fall from one level to another) and by mechanism of injury (fall from window). ${ }^{18}$

Data collected included address of fall; height of fall; age, race, gender, and home address of the person who fell; standardized Injury Severity Scores; and injury $I C D-9$ codes. Information from the registry was verified manually from all available charts. The ZIP code and address of each fall were used to determine occurrence within urban Cincinnati or nonurban Hamilton County. Urban was defined as within the city limits of Cincinnati, and nonurban was defined as the remaining Hamilton County area. When only the number of stories of the fall was recorded, each story was assigned a height of 12 feet. This height is based on other studies ${ }^{13}$ and building codes that require each story of a building to be 14 feet. Each fall was counted only once regardless of number of hospitalizations for the same incident.

\section{Statistical. Analysis}

Statistical analyses of rates of falls from windows and the associated $95 \%$ confidence intervals (CIs) were calculated based on age, race, gender, and place of residence. Mortality rates for falls from windows and all falls were calculated. Population data were obtained from the 1990 US Census. ${ }^{19}$

Data were analyzed with SAS (SAS Institute, Inc., Cary, NC) using GENMOD, a general model procedure that allows specification for the Poisson distribution, and Fisher exact tests were used to analyze population rates and individual differences according to race, gender, age, and location of fall. Linear regression, controlling for age, sex, and race, was used to analyze the relationship of Injury Severity score and height of fall. A $P$ value of less than .05 for a two-sided test was considered statistically significant.

\section{RESULTS}

From January 1, 1991, through December 31, 1997, there were 1,363 falls in Hamilton County, and $86(6.3 \%)$ were unintentional falls from windows. Death occurred in $4(4.7 \%)$ cases ( 1 child was dead on arrival), $78(90.7 \%)$ children were admitted and survived, and $4(4.7 \%)$ were treated and released.

Children younger than 5 years were at increased risk for falls from windows. There were 69 children less than 5 years old, for an annual incidence rate of $14.6 / 100,000$ (95\% CI, 11.5-18.6). There were 17 between the ages of 5 and 14 
years, for an annual incidence rate of $2.0 / 100,000$ (95\% CI, 1.2-3.2), which was significantly lower than for children younger than 5 years of age $(P<.0001)$.

Black children were at increased risk for falls from windows. There were 47 (55\%) black children, for an annual incidence rate of 13.1/100,000 (95\% CI, $9.8-$ $17.5)$, whereas $39(45 \%)$ children were white, for an incidence of $4.1 / 100,000(95 \%$ CI, 2.9-5.5) $(P<.002)$.

Males were also more likely to fall from a window compared with females. There were $55(64 \%)$ males, for an incidence rate of $8.2 / 100,000$ (95\% CI, 6.0-10.5), whereas 31 (36\%) were female $(4.8 / 100,000 ; 95 \% \mathrm{CI}, 3.3-6.8)(P<.02)$.

The rate of falls from windows was higher in urban areas compared to nonurban areas. Of the falls, 9 (10.5\%) occurred outside the child's home, and 1 child who lived in a suburban area fell from a dwelling in urban Cincinnati. Of the children who fell from a window, 64 (74\%) fell within the city of Cincinnati, and 22 fell in suburban or rural Hamilton County. The incidence of falls for children in Cincinnati was $11.6 / 100,000(95 \% \mathrm{CI}, 9.0-14.9)$, compared with $2.8 / 100,000$ (95\% CI, 1.8-4.3) $(P<.0002)$ (Table I). The highest rate of falls was seen in children less than 5 years of age who fell in the city of Cincinnati $(24.3 / 100,000)$.

All risk factors were examined statistically while controlling for other factors. After adjusting for all other variables, those who were black, urban, less than 5 years old, and male were associated independently with an increased risk of falling from a window. Separate analysis to determine if these factors were related found no statistically significant interaction.

There were $9(10 \%)$ children who fell less than 13 feet, $49(57 \%)$ fell 13-23 feet, and $26(30 \%)$ fell at least 24 feet. The height of fall for 2 children was un-

TABLE I Characteristics of Children Who Fell from Windows in Hamilton County (Cincinnati), from 1991 to $1997(\mathrm{~N}=86)$

\begin{tabular}{lcccc}
\hline & $\mathrm{n}(\%)$ & Rate $/ 100,000$ & $95 \% \mathrm{CI}$ & $P$ \\
\hline Age group & & & & \\
$\quad$ Aged 0-4 & $69(80)$ & 14.6 & $11.5-18.6$ & \\
$\quad$ Aged 5-14 & $17(20)$ & 2.0 & $1.2-3.2$ & $<.0001$ \\
Gender & & & & \\
$\quad$ Male & $55(64)$ & 8.2 & $6.0-10.5$ & \\
$\quad$ Female & $31(36)$ & 4.7 & $3.3-6.8$ & $<.02$ \\
Race & & & & \\
$\quad$ Black & $47(55)$ & 13.1 & $9.8-17.5$ & \\
$\quad$ White & $39(45)$ & 4.1 & $2.9-5.5$ & $<.002$ \\
Residence & & & & \\
$\quad$ Urban & $64(74)$ & 11.6 & $9.0-14.9$ & \\
$\quad$ Nonurban & $22(26)$ & 2.8 & $1.8-4.3$ & $<.0002$ \\
\hline
\end{tabular}


TABLE II Mean Injury Severity Score and Residence by Height of Fall $(\mathrm{N}=84)^{*}$

\begin{tabular}{lccc}
\hline Height of Fall & $\begin{array}{c}\text { Urban, } \\
\mathrm{n}(\%)\end{array}$ & $\begin{array}{c}\text { Nonurban, } \\
\mathrm{n}(\%)\end{array}$ & $\begin{array}{c}\text { Injury Severity Score } \\
\text { Mean (Range) }\end{array}$ \\
\hline $0-12$ feet & $7(11)$ & $2(9)$ & $4(0-9)$ \\
$13-23$ feet & $37(58)$ & $12(55)$ & $4(0-41)$ \\
$\geq 24$ feet & $19(30)$ & $7(32)$ & $8(0-41)$ \\
$\geq 30$ feet & $11(17)$ & $1(5)$ & $12(1-41)$ \\
\hline
\end{tabular}

*Height of fall of two children was unknown.

known. Of the 4 deaths, 3 occurred among children who fell at least 30 feet, and 11 of the 12 children who fell more than 30 feet fell in urban areas (Table II).

Fifteen children (17\%) were admitted to the intensive care unit (ICU); all but one child admitted to the ICU fell at least 13 feet. Significant injuries sustained included closed head injury (concussion or loss of consciousness with no abnormality on computerized tomography scan), skull/vertebral fractures and intracranial hemorrhage, extremity fractures, and severe trunk injuries, such as pneumothorax, lung contusion, and splenic laceration. A similar percentage of children in urban and nonurban areas sustained each type of injury (Table III). About one-third of children in both urban and nonurban areas sustained no significant injury. Of those who resided in the city of Cincinnati, 9 (14\%) had multiple injuries, whereas only $1(4 \%)$ child who lived outside the city had multiple injuries. All fatalities occurred among children who lived in the city of Cincinnati.

After excluding the 2 children who fell from an unknown height, 4 children who resided in Cincinnati had an Injury Severity score greater than 25, which is associated with high risk of death, whereas no child who lived outside the city had an Injury Severity score greater than 13 . Of the children, $90 \%$ fell more

TABLE III Injuries Sustained in Falls from Windows Among Urban and Nonurban Children $(\mathrm{N}=86)^{*}$

\begin{tabular}{lcc}
\hline Type of Injury & $\begin{array}{c}\text { Urban, } \mathrm{n}(\%) \\
(\mathrm{N}=64)\end{array}$ & $\begin{array}{c}\text { Nonurban, } \mathrm{n}(\%) \\
(\mathrm{N}=22)\end{array}$ \\
\hline $\begin{array}{l}\text { Closed head injury } \\
\text { Skull or vertebral fracture or }\end{array}$ & $13(20)$ & $3(14)$ \\
$\quad$ intracranial hemorrhage & $13(20)$ & $5(23)$ \\
Trunk injury & $8(13)$ & $4(18)$ \\
Extremity fracture & $20(31)$ & $3(14)$ \\
Minor/no injury & $22(34)$ & $8(36)$ \\
\hline
\end{tabular}

*Some children had multiple injuries; each injury counted separately. 
than 12 feet. Many children had minor injuries, but all deaths and the majority of severe injuries and ICU admissions occurred if children fell more than 12 feet. However, linear regression analysis of Injury Severity score and height of fall, controlling for age, sex, and race, did not reach statistical significance $(P=.2)$.

\section{DIsCUSSION}

Falls from windows cause substantial morbidity and mortality among children who reside in Hamilton County, Ohio. Children who were less than 5 years old had the highest rate of such falls. Black children and male children were also at increased risk of falling from a window. Children in urban areas were much more likely to fall than children in nonurban areas, and all deaths occurred within the city of Cincinnati. All children except one who fell more than 30 feet lived in urban Cincinnati, which likely reflects the higher number of multiplelevel dwellings in the city. Children who fell at least 30 feet seemed to be injured more severely, although this did not reach statistical significance. This may be due to the higher fall or a difference in landing surface.

Similar to our study, studies conducted in New York City and Chicago also found children who were less than 5 years old and male children to have higher rates of falls from heights. ${ }^{9,10,12-17}$ This is the first study, however, to test these rates for statistical significance. Our study thus confirms young children and male children are at highest risk, possibly due to impulsive behavior and limited appreciation of danger. The one previous study that examined race found no difference in rate of falls among white, black, and Hispanic children. ${ }^{17}$ This may be a reflection of different racial distribution in Cincinnati compared to other metropolitan areas.

No previous studies examined and compared rates of falls from windows for urban and nonurban children. Although such falls occur in both urban and nonurban settings, we found the incidence significantly higher among urban children in Hamilton County. This finding, however, should be interpreted cautiously. Data were obtained from one trauma registry at $\mathrm{CHMC}$, and death certificates were not reviewed. Since CHMC is the only Level 1 Pediatric Trauma Center in the Cincinnati area, with more than $99 \%$ of pediatric hospitalizations, it is unlikely than any children with significant trauma would be missed. It is possible, however, that children with no E code diagnosis were overlooked. Patients with minor injuries may not have been reported or may have been evaluated by other hospitals or clinics. Thus, it is possible that the incidence of falls from windows was similar for both urban and nonurban children, but all deaths and more severe injuries occurred among the urban children. 
The mortality rate in this study was within previously published rates of $0-25 \% .^{10,12-17}$ The deaths from falls from windows accounted for $4(80 \%)$ of the deaths from all falls recorded at this institution during the study period. Surprisingly, we did not find a correlation of height of fall and severity of injury. This is consistent with the one other study that examined severity of injury and height of fall. ${ }^{17}$ In our series, 3 of 4 deaths were of children who fell at least 30 feet, and falls from more than 12 feet were more likely to result in ICU admission and accounted for the most severe injuries.

Studies have demonstrated that as many as $90 \%$ of falls from windows can be prevented by the use of window guards. ${ }^{11,16}$ Due to the high mortality rate of children who fell from windows in New York City, ${ }^{9,10}$ the city's Public Health Department began the Children Can't Fly campaign in 1972, which involved reporting of falls from windows, community education, and free installation of window guards. ${ }^{11}$ After 2 years, a $50 \%$ decline in the incidence of falls from windows was reported, prompting passage of legislation mandating window guards. ${ }^{11}$ In a 10-year follow-up, Barlow estimated that such falls had decreased by $96 \%$ since the law was passed. ${ }^{16}$

There is no existing legislation mandating window guards in Cincinnati. Previous attempts to develop regulations, in 1991 and again in 1993, were thwarted by the lack of epidemiologic data and lobbying efforts by property owners. Perceived disadvantages to window guards include decreased exits in the event of fire, but guards may not be placed on fire escape windows, and the local fire department supports the use of window guards. In buildings with no air conditioning, there would be decreased air circulation in hot summer months since window guards limit the height windows can be opened. They also add some cost to low-income housing. Since significant injury occurred in higher falls, requiring window guards only on windows greater than 12 feet from the ground may be more cost-effective.

Falls from windows are an endemic, but preventable, problem that disproportionately affects urban children who are younger than 5 years. Strategies to educate landlords, parents, and policy makers about hazards surrounding windows and regulations to place window guards in multiple-unit dwellings are needed to prevent further morbidity and mortality from such falls.

\section{REFERENCES}

1. Rivara FP, Grossman DC. Prevention of traumatic deaths to children in the United States: how far have we come and where do we need to go? Pediatrics. 1996;97:791-797.

2. Hazinski M, Fancescutti LH, Lapidus GD, Micik S, Rivara FP. Pediatric injury prevention. Ann Emerg Med. 1993;22:456-467. 
3. Rivara FP, Grossman DC, Cummings P. Injury prevention: first of two parts. $N$ Engl I Med. 1997;337:543-548.

4. Rivara FP, Grossman DC, Cummings P. Injury prevention: second of two parts. $N$ Engl J Med. 1997;337:613-618.

5. Garrettson LK, Gallagher SS. Falls in children and youth. Pediatr Clin North Am. 1985; 32:153-162.

6. Rivara FP, Alexander B, Johnston B, Soderberg R. Population-based study of fall injuries in children and adolescents resulting in hospitalization or death. Pediatrics. 1993;92: 61-63.

7. National Center for Injury Prevention and Control. Mortality Statistics. Atlanta, GA: CDC; 1993-1995.

8. Hamilton County General Health District Division of Community Health Information Services. Hamilton County Injury Surveillance Report. Hamilton County General Health District; 1994-1996.

9. Bergner L, Mayer S, Harris D. Falls from heights: a childhood epidemic in an urban area. Am J Public Health. 1971;61:90-96.

10. Sieben RL, Leavitt JD, French JH. Falls as childhood accidents: an increasing urban risk. Pediatrics. 1971;47:886-892.

11. Spiegel CN, Lindaman FC. Children Can't Fly: a program to prevent childhood morbidity and mortality from window falls. Am J Public Health. 1977;67:1143-1146.

12. Smith MD, Burrington JD, Woolf AD. Injuries in children sustained in free falls: an analysis of 66 cases. J Trauma. 1975;15:987-991.

13. Meller JL, Shermeta DW. falls in urban children: a problem revisited. Am J Dis Child. 1987;141:1271-1275.

14. Mosenthal AC, Livingston DH, Elcavage J, Merritt S, Stucker S. Falls: epidemiology and strategies for prevention. J Trauma. 1995;38:753-756.

15. Lehman D, Schonfeld N. Falls from heights: a problem not just in the northeast. Pediatrics. 1993;92:121-124.

16. Barlow B, Niemirska M, Gandhi RP, Leblanc W. Ten years of experience with falls from a height in children. J Pediatr Surg. 1983;18:509-511.

17. Musemeche CA, Barthel M, Cosentino C, Reynolds M. Pediatric falls from heights. J Trauma. 1991;31:1347-1349.

18. US Department of Human Services. International Classification of Diseases, Ninth Revision, Clinical Modification. Washington, DC: US Department of Human Services; 1980. DHHS publication $80-1260$.

19. Bureau of Census. Census of Population and Housing: 1990. Washington, DC: US Department of Commerce; 1993. 